\title{
Hydrothermal Growth of Quasi-Monocrystal ZnO Thin Films and Their Application in Ultraviolet Photodetectors
}

\author{
Yung-Chun Tu, ${ }^{1}$ Shui-Jinn Wang, ${ }^{1,2}$ Tseng-Hsing Lin, ${ }^{1}$ Chien-Hsiung Hung, \\ Tsung-Che Tsai, ${ }^{1}$ Ru-Wen Wu, ${ }^{1}$ Kai-Ming Uang, ${ }^{3}$ and Tron-Min Chen ${ }^{3}$ \\ ${ }^{1}$ Institute of Microelectronics, Department of Electrical Engineering, National Cheng Kung University, Tainan 701, Taiwan \\ ${ }^{2}$ Advanced Optoelectronic Technology Center, National Cheng Kung University, Tainan 701, Taiwan \\ ${ }^{3}$ Department of Electrical Engineering, Wu Feng University, Chiayi 621, Taiwan
}

Correspondence should be addressed to Shui-Jinn Wang; sjwang@mail.ncku.edu.tw

Received 28 October 2014; Revised 31 January 2015; Accepted 2 February 2015

Academic Editor: Shyh-Jer Huang

Copyright (C) 2015 Yung-Chun Tu et al. This is an open access article distributed under the Creative Commons Attribution License, which permits unrestricted use, distribution, and reproduction in any medium, provided the original work is properly cited.

\begin{abstract}
Quasi-monocrystal $\mathrm{ZnO}$ film grown using the hydrothermal growth method is used for the fabrication of $\mathrm{Cu}{ }_{2} \mathrm{O} / \mathrm{ZnO}$ heterojunction $(\mathrm{HJ})$ ultraviolet photodetectors (UV-PDs). The $\mathrm{HJ}$ was formed via the sputtering deposition of $\mathrm{p}$-type $\mathrm{Cu}_{2} \mathrm{O}$ onto hydrothermally grown $\mathrm{ZnO}$ film (HTG-ZnO-film). The effect of annealing temperature in the nitrogen ambient on the photoluminescence spectra of the synthesized $\mathrm{ZnO}$ film was studied. The optoelectronic properties of $\mathrm{Cu}_{2} \mathrm{O} / \mathrm{ZnO}$ film with various $\mathrm{Cu}_{2} \mathrm{O}$ thicknesses $(250-750 \mathrm{~nm})$ under UV light $\left(365 \mathrm{~nm}\right.$; intensity: $\left.3 \mathrm{~mW} / \mathrm{cm}^{2}\right)$ were determined. The UV sensitivity of the HTGZnO-film-based UV-PDs and the sputtered ZnO-film-based UV-PDs were 55.6-fold $\left(S_{\mathrm{HTG}}\right)$ and 8.8 -fold $\left(S_{\text {sputter }}\right)$, respectively. The significant gain in sensitivity $\left(S_{\mathrm{HTG}} / S_{\text {sputter }}=630 \%\right)$ of the proposed ZnO-film-based device compared to that for the device based on sputtered film can be attributed to the improved photoelectric properties of quasi-monocrystal $\mathrm{ZnO}$ film.
\end{abstract}

\section{Introduction}

Ultraviolet photodetectors (UV-PDs) have attracted considerable interest for applications such as combustion engineering, missile plume detection, space-to-space communication, ozone layer monitoring, pollution monitoring, and flame detection $[1,2]$. UV-PDs have been fabricated on wide-directband-gap materials, including $\mathrm{ZnO}$ film obtained via spray deposition [3], GaN film obtained via plasma-assisted molecular beam epitaxy [4], and $\mathrm{TiO}_{2}$ obtained via hydrothermal growth (HTG) [5]. Among them, $\mathrm{ZnO}$ is a well-known direct wide band gap (3.37 eV at room temperature) and thermally stable n-type wurtzite semiconductor with a large exciton binding energy (about $60 \mathrm{meV}$ ) [6]. It has been widely investigated for its unique properties and potential applications in sensitive devices [7-15].

ZnO-based UV-PDs with a nanowire- (NW) type structure have drawn a lot of attention due to their ease of fabrication, low-temperature processing, and unique properties, such as high aspect ratio, high surface-to-volume ratio, and good carrier confinement in two dimensions, which benefit device performance [16]. However, UV-PDs based on $\mathrm{ZnO}$ NWs usually suffer from a relatively low junction area for photo detection. In addition, the integration of $\mathrm{ZnO}$ NWs into a working device remains a complicated, time-consuming, and uneconomical process, and there is a potential short-circuit problem for $\mathrm{ZnO}-\mathrm{NW}$-based UV-PDs $[17,18]$.

In this study, the fabrication of UV-PDs based on a p$\mathrm{Cu}_{2} \mathrm{O} / \mathrm{n}-\mathrm{ZnO}$ heterojunction $(\mathrm{HJ})$ is demonstrated. A quasimonocrystalline $\mathrm{ZnO}$ film grown on an indium tin oxide(ITO) coated glass substrate via the hydrothermal method is proposed to serve as the n-type semiconductor with improved photoelectric properties. Sputter deposition is used to deposit cupric oxide $\left(\mathrm{Cu}_{2} \mathrm{O}\right)$ as the p-type semiconductor. In addition to nontoxicity, low cost, and abundance of the starting material, $\mathrm{Cu}_{2} \mathrm{O}$ has a direct band gap of $2.0 \mathrm{eV}[19$, 20]. A sensing response with a wide spectrum range of $660 \sim$ $300 \mathrm{~nm}$ can be expected for the proposed $\mathrm{p}-\mathrm{Cu}_{2} \mathrm{O} / \mathrm{n}-\mathrm{ZnO}$ $\mathrm{HJ}$. The effects of $\mathrm{Cu}_{2} \mathrm{O}$ film thickness on the optoelectrical 


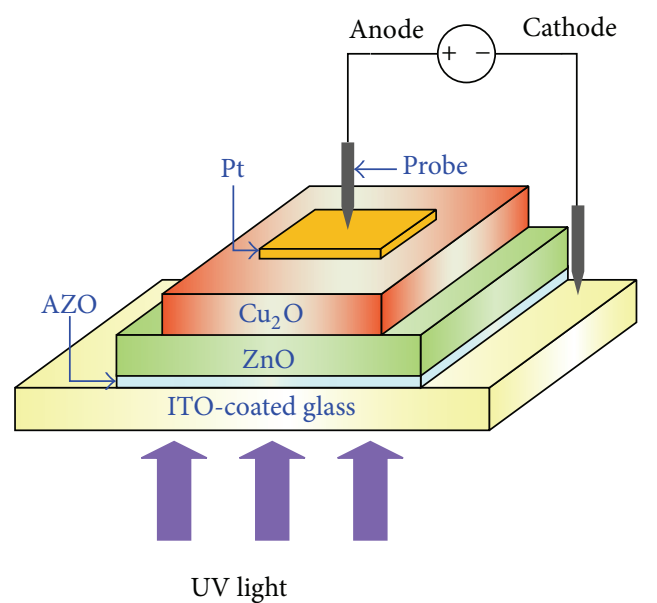

(a)
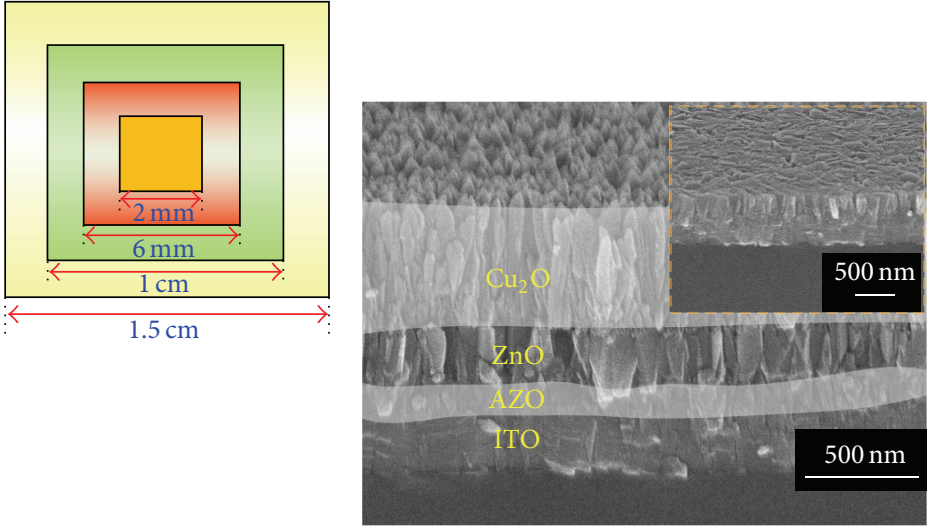

(b)

FIGURE 1: Schematic device structure and SEM images of prepared UV-PDs. (a) Schematic device structure and (b) tilted-view images of ZnO (HTG)/AZO/ITO and p- $\mathrm{Cu}_{2} \mathrm{O} / \mathrm{ZnO}$ (HTG)/AZO/ITO structures.

properties of UV-PDs are investigated. Comparisons between the performances of $\mathrm{p}-\mathrm{Cu}_{2} \mathrm{O} / \mathrm{n}-\mathrm{ZnO} \mathrm{UV}-\mathrm{PD}$ s based on $\mathrm{n}$ type $\mathrm{ZnO}$ films prepared via HTG and sputtering deposition, respectively, are made.

\section{Experimental Details}

Figure 1(a) shows the device structures of $\mathrm{ZnO}$-based UVPDs presented in this work. First, ITO-coated glass substrates were cleaned in a sonicating bath of acetone and isopropanol for $30 \mathrm{~min}$, rinsed in deionized water for $10 \mathrm{~min}$, and dried with nitrogen gas. The ITO-coated glass substrates were used for the fabrication of an n-side-up vertical-structured PD devices. Essentially, the ITO glass substrate is with a high electrical conductivity and high optical transparency ITO coating layer atop glass substrate, which could serve as an excellent transparent electrode for optoelectronic devices with bottomup fabrication process. In addition, it offers a much shorter length for forward current path $(\sim 1 \mu \mathrm{m})$, better current uniformity, and smaller series resistance, as compared with regular PD devices fabricated on glass substrate or insulated substrate. A $150 \mathrm{~nm}$ thick aluminum-doped zinc oxide (AZO) film was sputtered on ITO-coated glass substrates using radiofrequency (RF) sputtering with an RF power of $60 \mathrm{~W}$ for $90 \mathrm{~min}$ to serve as a seed layer. These samples were placed in a solution of $0.06 \mathrm{M}$ zinc nitrate hexahydrate $\left(\mathrm{Zn}\left(\mathrm{NO}_{3}\right)_{2} \cdot 6 \mathrm{H}_{2} \mathrm{O}\right)$ and hexamethylenetetramine $\left(\mathrm{C}_{6} \mathrm{H}_{12} \mathrm{~N}_{4}\right)$ at $70^{\circ} \mathrm{C}$ for $4 \mathrm{~h}$ for the growth of $\mathrm{ZnO}$ film $(300 \mathrm{~nm})$. At the end of the reaction, the samples were removed from the solution, washed with deionized water for $5 \mathrm{~min}$, and dried in nitrogen gas. Subsequently, $\mathrm{p}-\mathrm{Cu}_{2} \mathrm{O}$ films with three thicknesses $(250,500$, and $750 \mathrm{~nm})$ were sputtered onto the surface of the $\mathrm{ZnO}$ film by $\mathrm{RF}$ sputtering with a power of $90 \mathrm{~W}$ for 3,6 , and $9 \mathrm{~h}$, respectively, to complete the fabrication of $\mathrm{p}-\mathrm{Cu}_{2} \mathrm{O} / \mathrm{n}-\mathrm{ZnO} \mathrm{HJs}$. To examine the impact of annealing temperature on material quality, the samples were annealed in $\mathrm{N}_{2}$ gas at $300,400,500$, and $600^{\circ} \mathrm{C}$ for $10 \mathrm{~min}$, respectively.
Finally, an ohmic-contact electrode with $200 \mathrm{~nm}$ thick Pt film electrodes was deposited on the surface of the $\mathrm{p}-\mathrm{Cu}_{2} \mathrm{O}$ layer via e-gun evaporation. For comparison, $\mathrm{p}-\mathrm{Cu}_{2} \mathrm{O}(500 \mathrm{~nm}) / \mathrm{n}$ $\mathrm{ZnO}(300 \mathrm{~nm}) \mathrm{UV}-\mathrm{PD}$ s based on sputter-deposited $\mathrm{ZnO}$ film of the same thickness and annealed in $\mathrm{N}_{2}$ gas at $600^{\circ} \mathrm{C}$ for $10 \mathrm{~min}$ were also fabricated. All UV-PDs reported in this work have a die size of $1.5 \mathrm{~cm} \times 1.5 \mathrm{~cm}$ and a working area of $6 \mathrm{~mm} \times$ $6 \mathrm{~mm}$.

The surface morphologies and thicknesses of the grown $\mathrm{ZnO}$ film and $\mathrm{p}-\mathrm{Cu}_{2} \mathrm{O} / \mathrm{n}-\mathrm{ZnO}$ structure were characterized using scanning electron microscopy (SEM; Hitachi SU8000) at an accelerating voltage of $10 \mathrm{keV}$. The crystal structure and optical properties of $\mathrm{ZnO}$ films fabricated via $\mathrm{HTG}$ were examined using X-ray diffraction (XRD; D/MAX2500, Rigaku) with $\mathrm{CuK} \alpha$ (wavelength: $1.5418 \AA$ ) radiation at a scan step of $0.01^{\circ}(2 \theta)$, UV-visible-near-infrared double-beam spectrophotometry (U-3010 UV-VIS) with a 300-900 nm spectral range, and photoluminescence (PL) with an $\mathrm{He}-$ Cd laser as the light source using an excitation wavelength of $325 \mathrm{~nm}$ and a power of $3 \mathrm{~mW}$, respectively. The current density-voltage $(J-V)$ characteristics of the $\mathrm{p}-\mathrm{Cu}_{2} \mathrm{O} / \mathrm{n}-\mathrm{ZnO}$ film fabricated via HTG were measured using a Keithley 2636 voltage source instrument at room temperature in darkness and under 500-W Xe arc lamp illumination.

\section{Results and Discussion}

SEM images of the grown $\mathrm{ZnO}$ film and the prepared $\mathrm{p}$ $\mathrm{Cu}_{2} \mathrm{O}(500 \mathrm{~nm}) / \mathrm{n}-\mathrm{ZnO}$ structure on an AZO/ITO substrate are shown in Figure $1(\mathrm{~b})$. $\mathrm{ZnO}$ film with a controllable thickness $(300 \mathrm{~nm})$ was obtained by regulating the solution concentration, temperature, and growth time. As revealed by the inset in the figure, the grown $\mathrm{ZnO}$ film fully covered the AZO/ITO substrate, which effectively prevented the ptype material $\left(\mathrm{Cu}_{2} \mathrm{O}\right)$ from reaching the substrate during $\mathrm{HJ}$ formation and avoided the possible short-circuit problem usually encountered for ZnO-NW-based UV-PDs [17, 18]. 

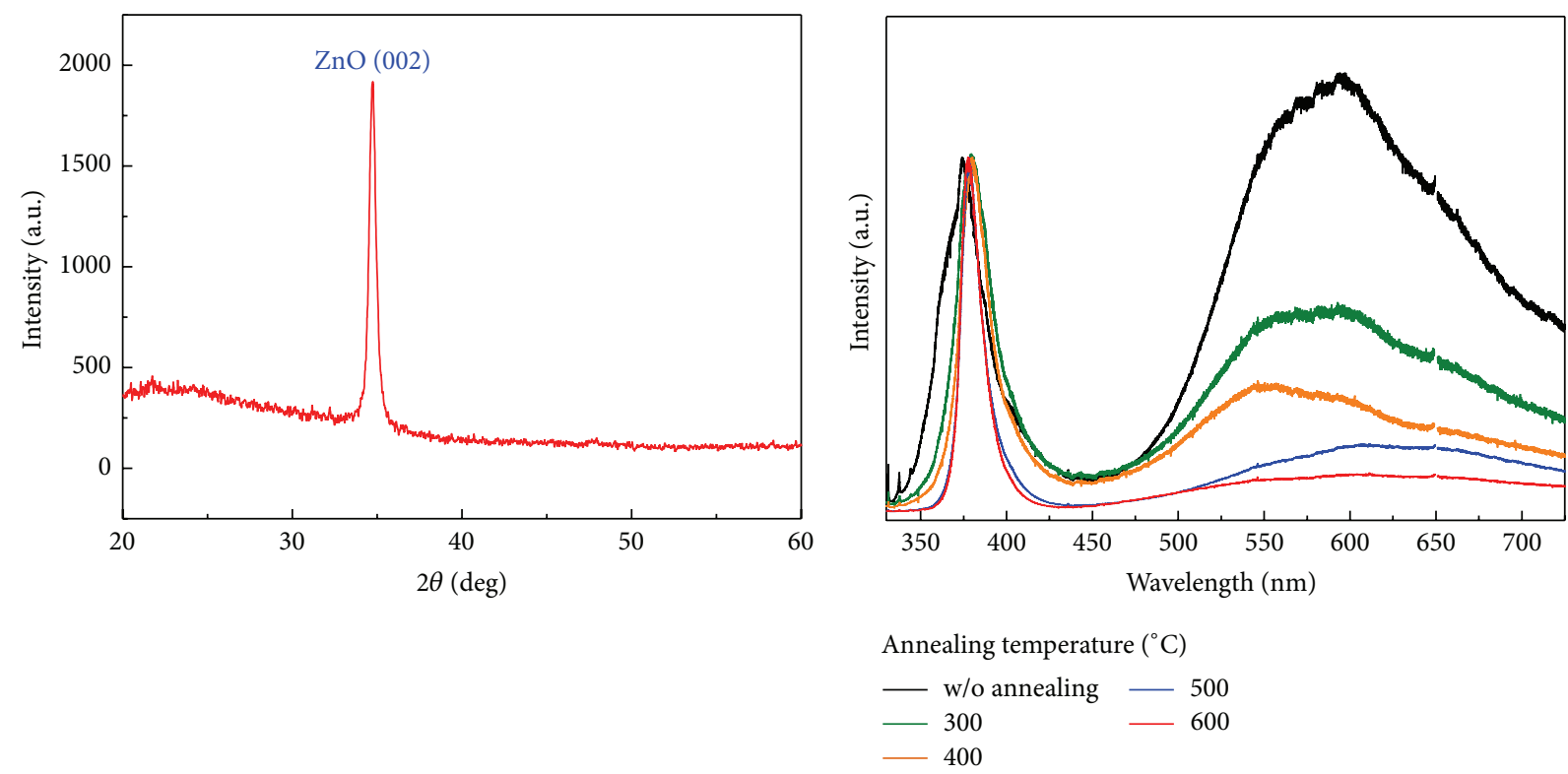

(a)

(b)

FIGURE 2: (a) XRD pattern of prepared n-ZnO film with quasi-monocrystal structure fabricated via HTG. (b) PL spectra of ZnO film (HTG) for various annealing temperatures in nitrogen.

The mechanism of the growth of the quasi-monocrystal $\mathrm{ZnO}$ film on the ITO-coated glass substrate can be attributed to the well-controlled parameters, such as solution concentration, temperature, and growth time, of the HTG process. It has been reported that these parameters have a strong impact on the aspect ratio of ZnO NWs [21]. A lower HTG temperature, higher solution concentration, and longer growth time lead to a larger diameter of $\mathrm{ZnO} \mathrm{NWs}$. $\mathrm{ZnO}$ films were formed through the aggregation of NWs and then followed by self-organized growth among interconnected NWs [22]. As shown in Figure 1(b), the sputter-deposited $\mathrm{p}-\mathrm{Cu}_{2} \mathrm{O}$ film had a dense NW-like morphology. It is speculated that the sputtering power used in this work might have enough energy to increase the nucleation kinetics during sputter deposition, which is in good agreement with the experimental findings on sputter-deposited $\mathrm{Cu}_{2} \mathrm{O}$ films with various sputtering powers $[23,24]$.

The material properties of the prepared $\mathrm{ZnO}$ film were analyzed by XRD and PL, with the results shown in Figure 2. On the basis of the diffraction peak that corresponded to the (002) plane shown in Figure 2(a), the $\mathrm{ZnO}$ film fabricated via HTG was indexed to have a hexagonal wurtzite signal according to the standard JCPDS card [25]. This indicates that $\mathrm{ZnO}$ films fabricated via HTG are mainly formed via self-organized growth interconnections of closely packed crystalline columnar $\mathrm{ZnO}$ with the $c$-axis vertical to the substrate surface. It is believed that the $\mathrm{ZnO}$ films fabricated via HTG in the present work do have a quasi-monocrystalline structure. The influence of thermal annealing conditions on the PL spectra of the $\mathrm{ZnO}$ films fabricated via HTG on a controlled wafer was examined. The results are shown in Figure 2(b). The $\mathrm{ZnO}$ films with and without annealing exhibit UV and visible (VIS) emission peaks with different full widths at half maximum (FWHM) values for the former and different intensities for the latter. The UV and VIS emission peaks are attributed to free exciton recombination and a transition of excited optical centers from a deep level to the valence level arising from singly ionized oxygen vacancies [26], respectively. Our results show that the intensity of the VIS light emission peak decreases with increasing annealing temperature. This might be due to the nitrogen atmosphere suppressing the reevaporation of oxygen during annealing. At the same time, nonradiative-related defects may have been reduced, increasing UV emission [27]. As a result, a considerable decay in VIS emission intensity of the nitrogenannealed $\mathrm{ZnO}$ films fabricated via HTG was observed.

Figure 3 shows the measured $J-V$ curves of the p$\mathrm{Cu}_{2} \mathrm{O} / \mathrm{ZnO}$ film (HTG) HJs in darkness. The fabricated HJs with various $\mathrm{Cu}_{2} \mathrm{O}$ thicknesses after annealing at $600^{\circ} \mathrm{C}$ in nitrogen all exhibit well-defined rectifying behaviors. In this work, the electron concentrations in the annealed $\mathrm{ZnO}$ film and the hole concentration in the annealed $\mathrm{Cu}_{2} \mathrm{O}$ are $1 \sim 2 \times$ $10^{16} \mathrm{~cm}^{-3}$ and $2 \sim 3 \times 10^{15} \mathrm{~cm}^{-3}$, respectively, based on Hall measurements. The width of depletion region corresponding to the abovementioned carrier concentrations is $350 \sim 500 \mathrm{~nm}$ $\left(\mathrm{Cu}_{2} \mathrm{O}: 300 \sim 400 \mathrm{~nm} ; \mathrm{ZnO}: 50 \sim 90 \mathrm{~nm}\right)$. The band offsets between $\mathrm{ZnO}$ and $\mathrm{Cu}_{2} \mathrm{O}$ are $\Delta E_{c}=0.9 \mathrm{eV}$ and $\Delta E_{v}=$ $2.17 \mathrm{eV}$ [28], respectively. Note that the sample with $250 \mathrm{~nm}$ thick $\mathrm{Cu}_{2} \mathrm{O}$ film exhibits the highest forward current, which can be attributed to the thickness of the $\mathrm{Cu}_{2} \mathrm{O}$ layer being insufficient, and as a result, both the built-in voltage and the depletion region were limited. Similarly, the decrease in the forward current of the $750 \mathrm{~nm}$ thick $\mathrm{Cu}_{2} \mathrm{O}$ device might be due to the series resistance of the thicker $\mathrm{Cu}_{2} \mathrm{O}$ layer. The annealed sample with $500 \mathrm{~nm}$ thick $\mathrm{Cu}_{2} \mathrm{O}$ film is the most suitable for UV-PDs because it has the best trade-off between 


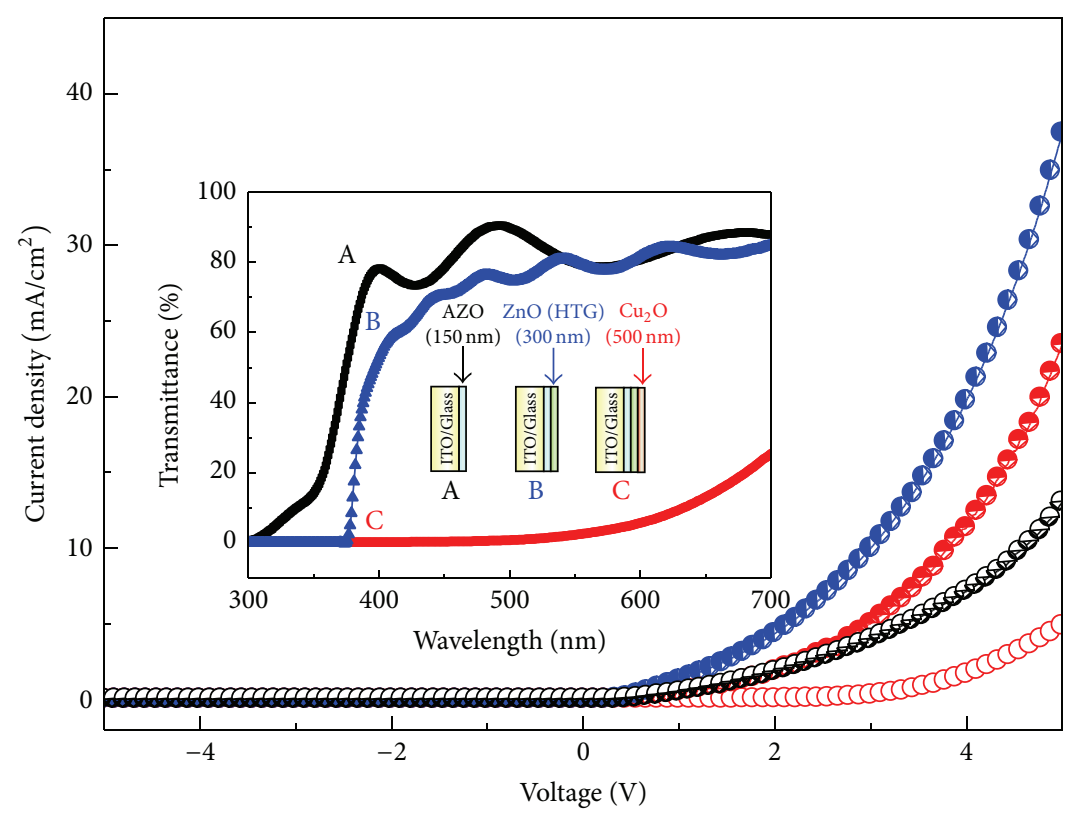

$\mathrm{Cu}_{2} \mathrm{O}$ thickness $(\mathrm{nm})$

w/o annealing $\quad \mathrm{w} /$ annealing

$\multimap 500 \quad 500$

$\rightarrow-250$

$\multimap 750$

Figure 3: Experimental $J-V$ curves of p- $\mathrm{Cu}_{2} \mathrm{O} / \mathrm{ZnO}$ film (HTG) $\mathrm{HJs}$ in darkness. Inset shows the measured transmittance of the prepared samples after annealing. ITO-coated glass substrate after AZO (150 nm) layer deposition (structure A), with an additional ZnO film (HTG) $(300 \mathrm{~nm})$ (structure $\mathrm{B})$, and with a $\mathrm{Cu}_{2} \mathrm{O}$ layer $(500 \mathrm{~nm})$ atop structure $\mathrm{B}$ (structure $\mathrm{C}$ ).

built-in voltage/depletion width and the series resistance. The annealed device with $500 \mathrm{~nm}$ thick $\mathrm{Cu}_{2} \mathrm{O}$ film exhibits a lower forward threshold voltage $\left(V_{\text {th }}\right.$ at $\left.0.1 \mathrm{~mA} / \mathrm{cm}^{2}\right)$ of $0.5 \mathrm{~V}$ and a lower leakage current $\left(J_{r}\right)$ of $9 \times 10^{-8} \mathrm{~A} / \mathrm{cm}^{2}$ biased at $-1 \mathrm{~V}$ compared to those of the unannealed devices $\left(V_{\text {th }}=2.5 \mathrm{~V}\right.$; $\left.J_{r}=1.37 \times 10^{-7} \mathrm{~A} / \mathrm{cm}^{2}\right)$. These results suggest that $\mathrm{ZnO}$ films fabricated via HTG have improved material quality, including reduced defect states and enhanced crystallinity, after thermal annealing [29]. The light transmittances of the annealed samples including AZO film $(150 \mathrm{~nm})$ and $\mathrm{ZnO}$ film $(300 \mathrm{~nm})$ fabricated via $\mathrm{HTG} / \mathrm{AZO}$ and $\mathrm{Cu}_{2} \mathrm{O}$ film $(500 \mathrm{~nm}) / \mathrm{ZnO} / \mathrm{AZO}$ prepared atop the ITO glass substrate are compared in the inset of Figure 3. The $\mathrm{Cu}_{2} \mathrm{O} / \mathrm{ZnO} / \mathrm{AZO}$ structure has the lowest transmittance (0 1\%) in the UV light spectrum, indicating that both $\mathrm{Cu}_{2} \mathrm{O}$ and $\mathrm{ZnO}$ films have strong UV light absorptivity.

Figure 4 shows the measured reverse-biased $J$ - $V$ characteristics of the prepared $\mathrm{HJ}$ s based on $\mathrm{ZnO}$ films fabricated via HTG in the dark or under various illumination conditions. The experimental results indicate that unannealed UV-PDs are responsive to both UV and VIS light and that annealed UV-PDs are only sensitive to UV light, avoiding VIS interference during UV detection. The improved performance of the annealed UV-PDs can be attributed to the suppression of structural and interfacial defects, which decreases the component of photocurrent through defect states to the conduction band in the ambient in the presence of VIS light.

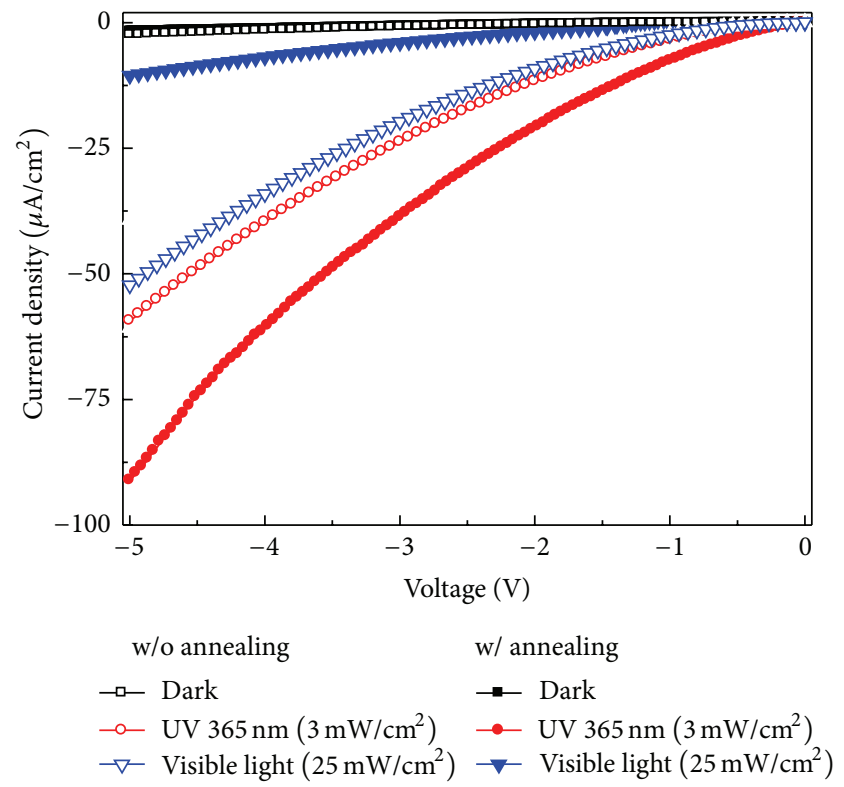

FIGURE 4: Comparisons of experimental $J-V$ curves of $\mathrm{p}-\mathrm{Cu}_{2} \mathrm{O} / \mathrm{ZnO}$ (HTG) sample with and without thermal annealing.

Figure 5 shows the spectral response of the annealed UV-PDs measured under a reverse bias of $1 \mathrm{~V}$. It was found that the responsibility shows a cutoff at around $370 \sim 390 \mathrm{~nm}$ and the 


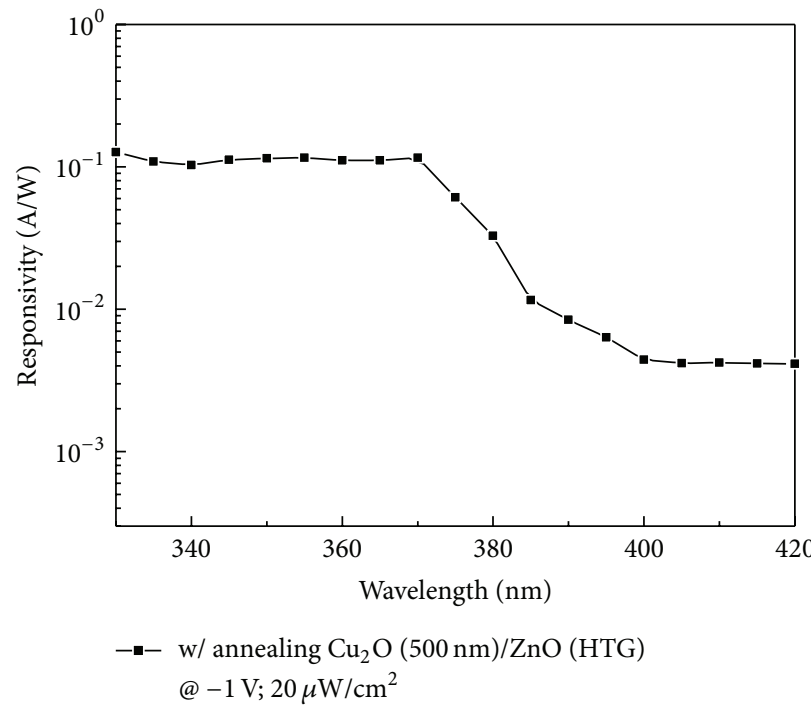

FIGURE 5: Spectral response of the $\mathrm{p}-\mathrm{Cu}_{2} \mathrm{O} / \mathrm{ZnO}$ (HTG) sample UV sensor measured at a reverse bias of $1 \mathrm{~V}$.

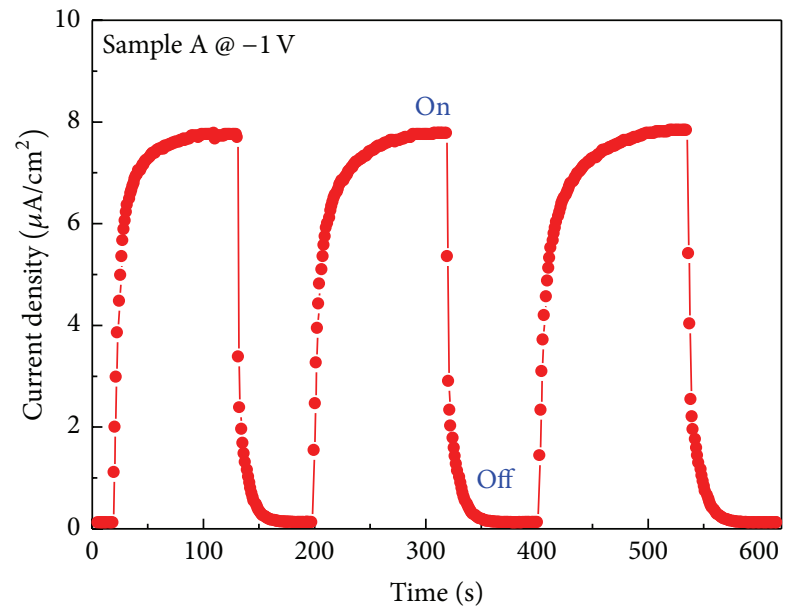

(a)

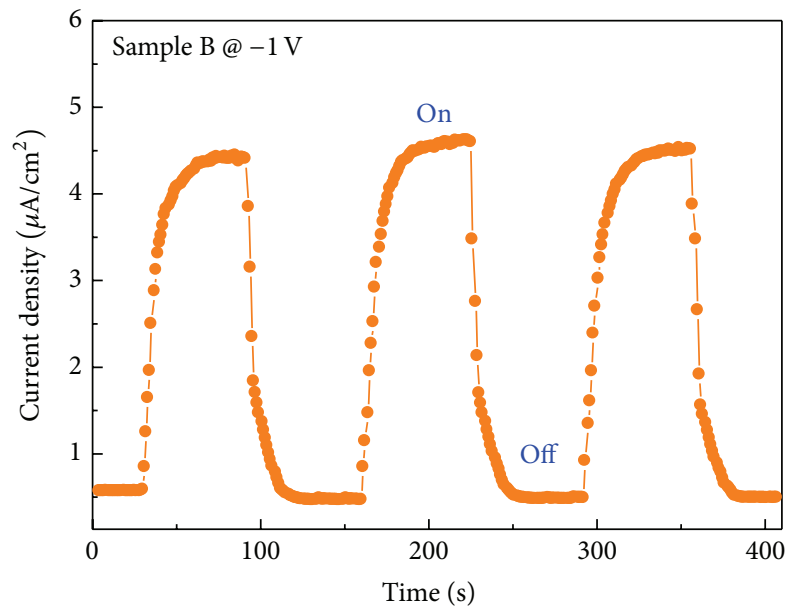

(b)

FIGURE 6: Transient response of photocurrent density of fabricated devices based on ZnO film (HTG) (sample A) and sputter-deposited ZnO film (sample B). Wavelength and intensity of UV light are $365 \mathrm{~nm}$ and $3 \mathrm{~mW} / \mathrm{cm}^{2}$, respectively.

response of the UV region $(330 \sim 370 \mathrm{~nm})$ is nearly constant which is higher than that of in the visible spectrum by one order more.

Figure 6 shows the dynamic photoresponses of the UVPDs annealed at $600^{\circ} \mathrm{C}$ in nitrogen based on hydrothermally grown and sputter-deposited $\mathrm{ZnO}$ films, respectively (referred to as samples $\mathrm{A}$ and $\mathrm{B}$, resp.). Note that the thicknesses of the $\mathrm{p}-\mathrm{Cu}_{2} \mathrm{O}$ and $\mathrm{ZnO}$ layers were 500 and $300 \mathrm{~nm}$, respectively. The response times of the devices with sputter-deposited and hydrothermally grown films are about 20 and $22 \mathrm{~s}$ and the recovery times are about 26 and $30 \mathrm{~s}$, respectively. The device based on hydrothermally grown film shows a 55.6 -fold increase in the current at $-1 \mathrm{~V}$ with irradiation under $365 \mathrm{~nm}$ UV light and a power density of $3 \mathrm{~mW} / \mathrm{cm}^{2}$ compared to that for the device based on sputterdeposited film. The enhanced photoresponse of the former device is mainly attributed to the hydrothermal-grown $\mathrm{ZnO}$ film which was formed by aggregated single-crystalline $\mathrm{ZnO}$ nanowires with the $c$-axis vertical to the substrate surface. It provides parallel current paths through the coalesced singlecrystalline $\mathrm{ZnO}$ nanowires with much better optoelectronic properties, as compared with the sputter-deposited $\mathrm{ZnO}$ films with polycrystalline or amorphous structure. In addition, thermal annealing offers further improvement in the $\mathrm{ZnO}$ film quality through suppressing nonradiative-related defects as revealed from PL measurements.

In recent years, $\mathrm{ZnO}$-based UV PDs have been widely reported. Lee et al. reported the $\mathrm{RF}$ sputtering of $\mathrm{p}-\mathrm{NiO}$ film onto the surface of the $\mathrm{ZnO} \mathrm{NW}$ by MOCVD and the measured UV sensitivity, response times, and recovery times were 11.3 -fold, $72 \mathrm{~s}$, and $110 \mathrm{~s}$, respectively. Wang et al. reported the hydrothermal growth of $\mathrm{ZnO} \mathrm{NW}$ on $\mathrm{CuO}$ 
nanowires and the measured UV sensitivity, response times, and recovery times were 3 -fold, $100 \mathrm{~s}$, and $141 \mathrm{~s}$, respectively. More recently, Guo et al. presented the hydrothermal growth of $\mathrm{ZnO}$ nanorod arrays on $\mathrm{NiO}$ nanowires and the measured UV sensitivity, response times, and recovery times were 23-fold, $55 \mathrm{~s}$, and $70 \mathrm{~s}$, respectively [30-32]. In this work, the preparation of $\mathrm{p}-\mathrm{Cu}_{2} \mathrm{O} / \mathrm{ZnO}$ film (HTG) $\mathrm{HJs}$ is with measured UV sensitivity, response times, and recovery times which were 55.6-fold, $20 \mathrm{~s}$, and $26 \mathrm{~s}$, respectively, which are comparably much better than those of UV-PDs reported in the literature mentioned above.

\section{Conclusion}

The preparation of $\mathrm{p}-\mathrm{Cu}_{2} \mathrm{O} / \mathrm{ZnO}$ film (HTG) HJs with good UV sensitivity was demonstrated. $\mathrm{ZnO}$ films with a controllable thickness $(300 \mathrm{~nm})$ that fully covered the AZO/ITO substrate were obtained by suitably regulating the solution concentration, temperature, and growth time of the HTG process. According to the XRD and PL analyses, the $\mathrm{ZnO}$ film fabricated via HTG had a quasi-monocrystalline structure. Thermal annealing in nitrogen at $600^{\circ} \mathrm{C}$ effectively eliminated defect states in the $\mathrm{ZnO}$ films, suppressing VIS interference during UV light detection. Experimental results reveal that the $\mathrm{p}-\mathrm{Cu}_{2} \mathrm{O} / \mathrm{n}-\mathrm{ZnO}$ films fabricated via HTG have a fairly good response to UV light $\left(3 \mathrm{~mW} / \mathrm{cm}^{2}\right.$ at $\left.365 \mathrm{~nm}\right)$ with an increase in the photocurrent of about 55.6-fold compared to that for the device based on sputter-deposited film. It is expected that the HJs based on ZnO film fabricated via HTG will be suitable for future optoelectronic applications.

\section{Conflict of Interests}

The authors declare that there is no conflict of interests regarding the publication of this paper.

\section{Acknowledgments}

This work was supported by the Ministry of Science and Technology (MOST) of Taiwan, under Grant MOST 1032221-E-006-132 and the National Science Council (NSC) of Taiwan, under Grant NSC 102-2221-E-006-217-MY2. The authors would like to thank the National Nano Device Laboratories and the Center for Micro/Nano Science and Technology, National Cheng Kung University, Taiwan, for equipment access and financial and technical support.

\section{References}

[1] K. J. Chen, F. Y. Hung, S. J. Chang, and S. J. Young, "Optoelectronic characteristics of UV photodetector based on $\mathrm{ZnO}$ nanowire thin films," Journal of Alloys and Compounds, vol. 479, no. 1-2, pp. 674-677, 2009.

[2] K. Liu, M. Sakurai, and M. Aono, "ZnO-based ultraviolet photodetectors," Sensors, vol. 10, no. 9, pp. 8604-8634, 2010.

[3] S. I. Inamdar and K. Y. Rajpure, "High-performance metalsemiconductor-metal UV photodetector based on spray deposited $\mathrm{ZnO}$ thin films," Journal of Alloys and Compounds, vol. 595, pp. 55-59, 2014.
[4] M. Z. M. Yusoff, A. Mahyuddin, Z. Hassan et al., "AlN/GaN/AlN heterostructures grown on Si substrate by plasma-assisted MBE for MSM UV photodetector applications," Materials Science in Semiconductor Processing, vol. 29, pp. 231-237, 2015.

[5] Y. Xie, L. Wei, Q. Li et al., "High-performance self-powered UV photodetectors based on $\mathrm{TiO}_{2}$ nano-branched arrays," Nanotechnology, vol. 25, no. 7, Article ID 075202, 2014.

[6] S.-P. Chang, S.-J. Chang, C.-Y. Lu et al., "A ZnO nanowire-based humidity sensor," Superlattices and Microstructures, vol. 47, no. 6, pp. 772-778, 2010.

[7] F. S. Tsai, S. J. Wang, Y. C. Tu et al., "Preparation of p-SnO/n$\mathrm{ZnO}$ heterojunction nanowire arrays and their optoelectronic characteristics under UV illumination," Applied Physics Express, vol. 4, no. 2, Article ID 025002, pp. 1-3, 2011.

[8] F.-S. Tsai and S.-J. Wang, "Enhanced sensing performance of relative humidity sensors using laterally grown $\mathrm{ZnO}$ nanosheets," Sensors and Actuators B: Chemical, vol. 193, pp. 280-287, 2014.

[9] D. An, Y. Li, X. Lian, Y. Zou, and G. Deng, "Synthesis of porous $\mathrm{ZnO}$ structure for gas sensor and photocatalytic applications," Colloids and Surfaces A: Physicochemical and Engineering Aspects, vol. 447, pp. 81-87, 2014.

[10] T.-Y. Chen, H.-I. Chen, C.-S. Hsu et al., "ZnO-nanorod-based ammonia gas sensors with underlying $\mathrm{Pt} / \mathrm{Cr}$ interdigitated electrodes," IEEE Electron Device Letters, vol. 33, no. 10, pp. 1486-1488, 2012.

[11] P.-Y. Yang, J.-L. Wang, W.-C. Tsai et al., "Photoresponse of hydrothermally grown lateral $\mathrm{ZnO}$ nanowires," Thin Solid Films, vol. 518, no. 24, pp. 7328-7332, 2010.

[12] C. Tian, D. Jiang, B. Li et al., "Performance enhancement of ZnO UV photodetectors by surface plasmons," ACS Applied Materials and Interfaces, vol. 6, no. 3, pp. 2162-2166, 2014.

[13] S. P. Chang, C. Y. Lu, S. J. Chang, Y. Z. Chiou, T. J. Hsueh, and C. L. Hsu, "Electrical and optical characteristics of UV photodetector with interlaced $\mathrm{ZnO}$ nanowires," IEEE Journal on Selected Topics in Quantum Electronics, vol. 17, no. 4, pp. 990995, 2011.

[14] H. Y. Chen, K. W. Liu, X. Chen et al., "Realization of a selfpowered ZnO MSM UV photodetector with high responsivity using an asymmetric pair of Au electrodes," Journal of Materials Chemistry C, vol. 2, no. 45, pp. 9689-9694, 2014.

[15] S. P. Chang, R. W. Chuang, S. J. Chang, C. Y. Lu, Y. Z. Chiou, and S. F. Hsieh, "Surface $\mathrm{HCl}$ treatment in $\mathrm{ZnO}$ photoconductive sensors," Thin Solid Films, vol. 517, no. 17, pp. 5050-5053, 2009.

[16] Y. B. Li, F. D. Valle, M. Simonnet, I. Yamada, and J.-J. Delaunay, "High-performance UV detector made of ultra-long $\mathrm{ZnO}$ bridging nanowires," Nanotechnology, vol. 20, no. 4, Article ID 045501, 2009.

[17] L. Luo, Y. Zhang, S. S. Mao, and L. Lin, "Fabrication and characterization of $\mathrm{ZnO}$ nanowires based UV photodiodes," Sensors and Actuators A: Physical, vol. 127, no. 2, pp. 201-206, 2006.

[18] J. Y. Wang, C. Y. Lee, Y. T. Chen et al., "Double side electroluminescence from $\mathrm{p}-\mathrm{NiO} / \mathrm{n}-\mathrm{ZnO}$ nanowire heterojunctions," Applied Physics Letters, vol. 95, no. 13, Article ID 131117, pp. 1-3, 2009.

[19] X. Zou, H. Fan, Y. Tian, and S. Yan, "Synthesis of $\mathrm{Cu}_{2} \mathrm{O} / \mathrm{ZnO}$ hetero-nanorod arrays with enhanced visible light-driven photocatalytic activity," CrystEngComm, vol. 16, no. 6, pp. 1149-1156, 2014.

[20] M. Izaki, T. Shinagawa, K.-T. Mizuno, Y. Ida, M. Inaba, and A. Tasaka, "Electrochemically constructed p-Cu2O/n- $\mathrm{ZnO}$ heterojunction diode for photovoltaic device," Journal of Physics D: Applied Physics, vol. 40, no. 11, pp. 3326-3329, 2007. 
[21] M. Guo, P. Diao, and S. Cai, "Hydrothermal growth of wellaligned $\mathrm{ZnO}$ nanorod arrays: dependence of morphology and alignment ordering upon preparing conditions," Journal of Solid State Chemistry, vol. 178, no. 6, pp. 1864-1873, 2005.

[22] N. Yu, L. Du, H. Du et al., "Synthesis of $\mathrm{ZnO}$ film on PGaN/Si(111) by one-step hydrothermal method," Thin Solid Films, vol. 550, pp. 206-209, 2014.

[23] A. S. Reddy, H.-H. Park, V. S. Reddy et al., "Effect of sputtering power on the physical properties of dc magnetron sputtered copper oxide thin films," Materials Chemistry and Physics, vol. 110, no. 2-3, pp. 397-401, 2008.

[24] Z. G. Yin, H. T. Zhang, D. M. Goodner et al., "Two-dimensional growth of continuous $\mathrm{Cu}_{2} \mathrm{O}$ thin films by magnetron sputtering," Applied Physics Letters, vol. 86, no. 6, Article ID 061901, pp. 1-3, 2005.

[25] Y.-C. Tu, S.-J. Wang, J.-C. Lin et al., "Light output improvement of GaN-based light-emitting diodes using hydrothermally grown $\mathrm{ZnO}$ nanotapers," Japanese Journal of Applied Physics, vol. 52, no. 6, Article ID 06GG13, 2013.

[26] H. S. Kang, J. S. Kang, S. S. Pang, E. S. Shim, and S. Y. Lee, "Variation of light emitting properties of $\mathrm{ZnO}$ thin films depending on post-annealing temperature," Materials Science and Engineering B, vol. 102, no. 1-3, pp. 313-316, 2003.

[27] L. H. Quang, S. J. Chua, K. P. Loh, and E. Fitzgerald, “The effect of post-annealing treatment on photoluminescence of $\mathrm{ZnO}$ nanorods prepared by hydrothermal synthesis," Journal of Crystal Growth, vol. 287, no. 1, pp. 157-161, 2006.

[28] H. T. Hsueh, S. J. Chang, W. Y. Weng et al., "Fabrication and characterization of coaxial p-copper oxide/n- $\mathrm{ZnO}$ nanowire photodiodes," IEEE Transactions on Nanotechnology, vol. 11, no. 1, pp. 127-133, 2012.

[29] K. H. Tam, C. K. Cheung, Y. H. Leung et al., "Defects in $\mathrm{ZnO}$ nanorods prepared by a hydrothermal method," Journal of Physical Chemistry B, vol. 110, no. 42, pp. 20865-20871, 2006.

[30] T. Guo, Y. Luo, Y. Zhang, Y.-H. Lin, and C.-W. Nan, "Controllable growth of $\mathrm{ZnO}$ nanorod arrays on $\mathrm{NiO}$ nanowires and their high UV photoresponse current," Crystal Growth and Design, vol. 14, no. 5, pp. 2329-2334, 2014.

[31] K. R. Lee, B. O. Jung, S. W. Cho, K. Senthil, and H. K. Cho, "Semitransparent all-oxide $\mathrm{p}-\mathrm{NiO} / \mathrm{n}-\mathrm{ZnO}$ nanowire ultraviolet photosensors," Journal of Materials Research, vol. 28, no. 18, pp. 2605-2610, 2013.

[32] S.-B. Wang, C.-H. Hsiao, S.-J. Chang et al., "ZnO branched nanowires and the $\mathrm{p}-\mathrm{CuO} / \mathrm{n}-\mathrm{ZnO}$ heterojunction nanostructured photodetector," IEEE Transactions on Nanotechnology, vol. 12, no. 2, pp. 263-269, 2013. 

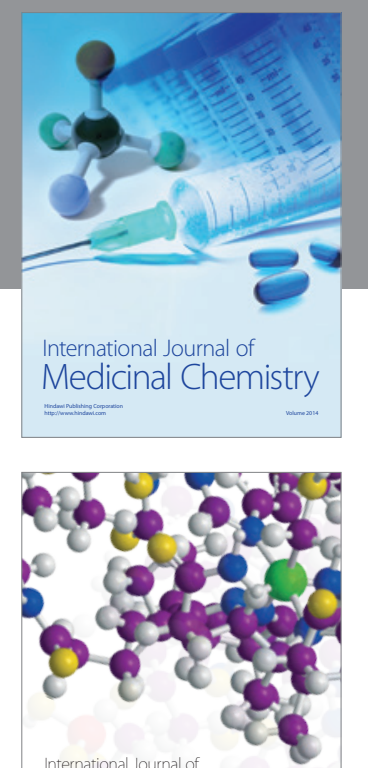

\section{Carbohydrate} Chemistry

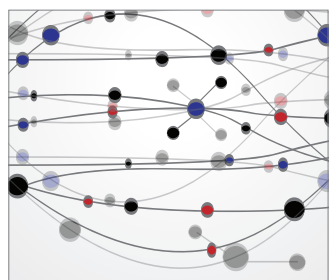

The Scientific World Journal
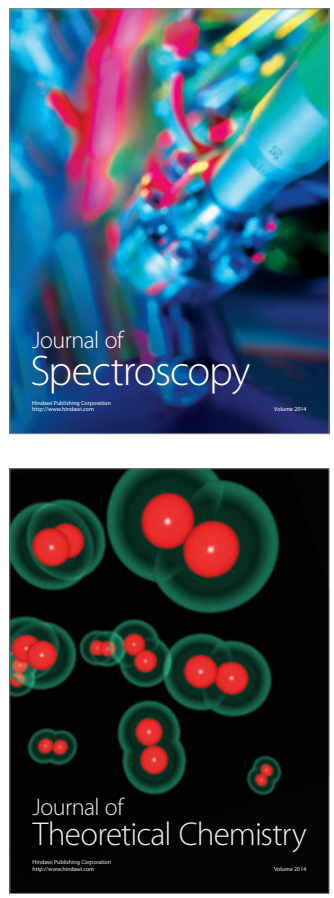
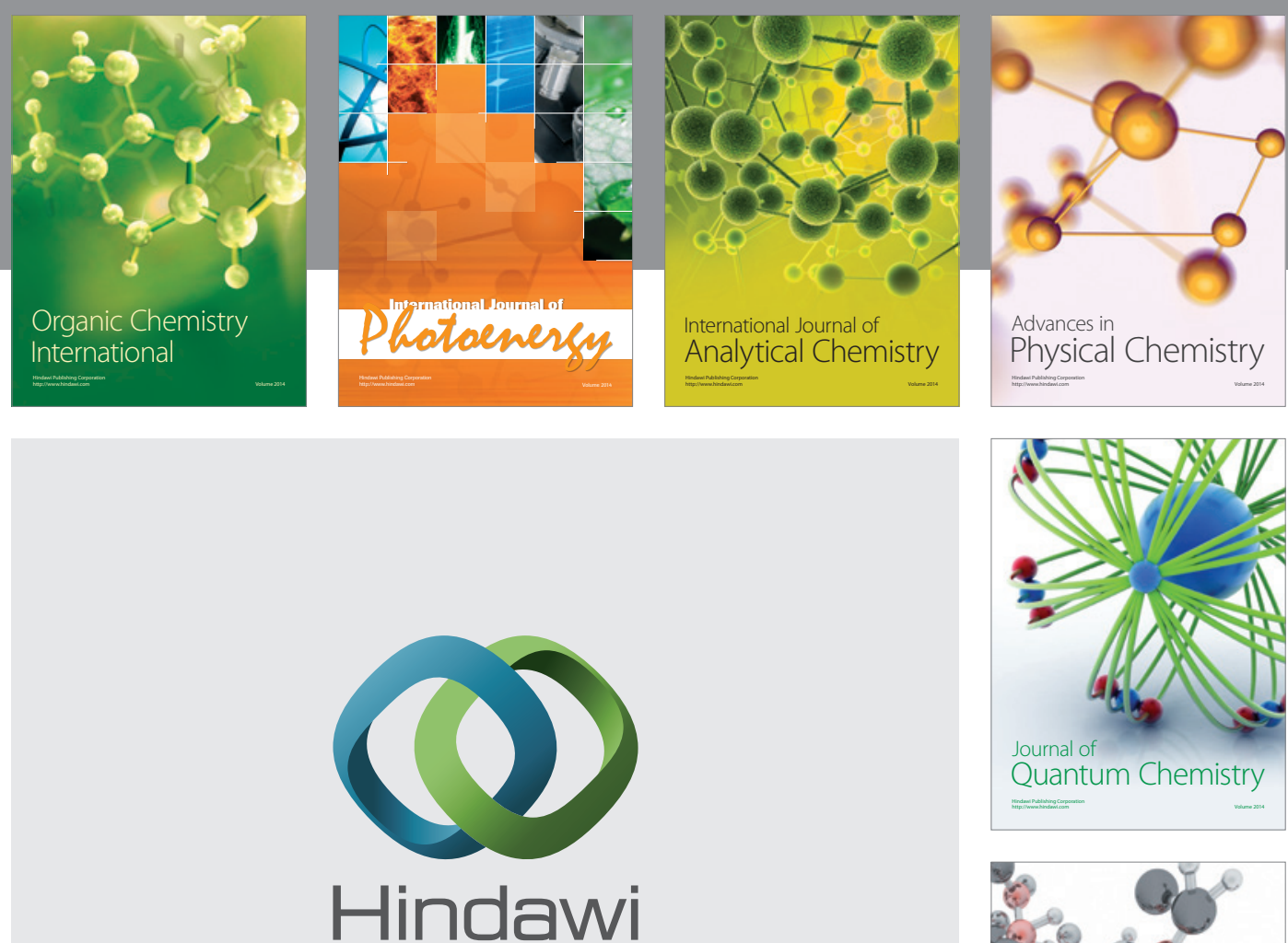

Submit your manuscripts at

http://www.hindawi.com

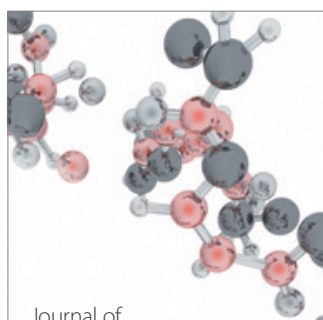

Analytical Methods

in Chemistry

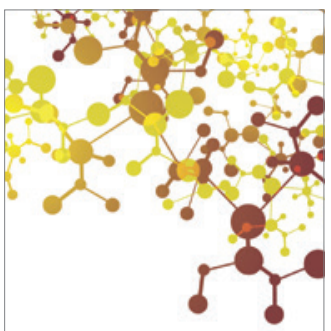

Journal of

Applied Chemistry

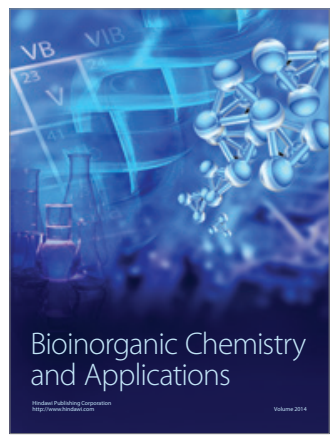

Inorganic Chemistry
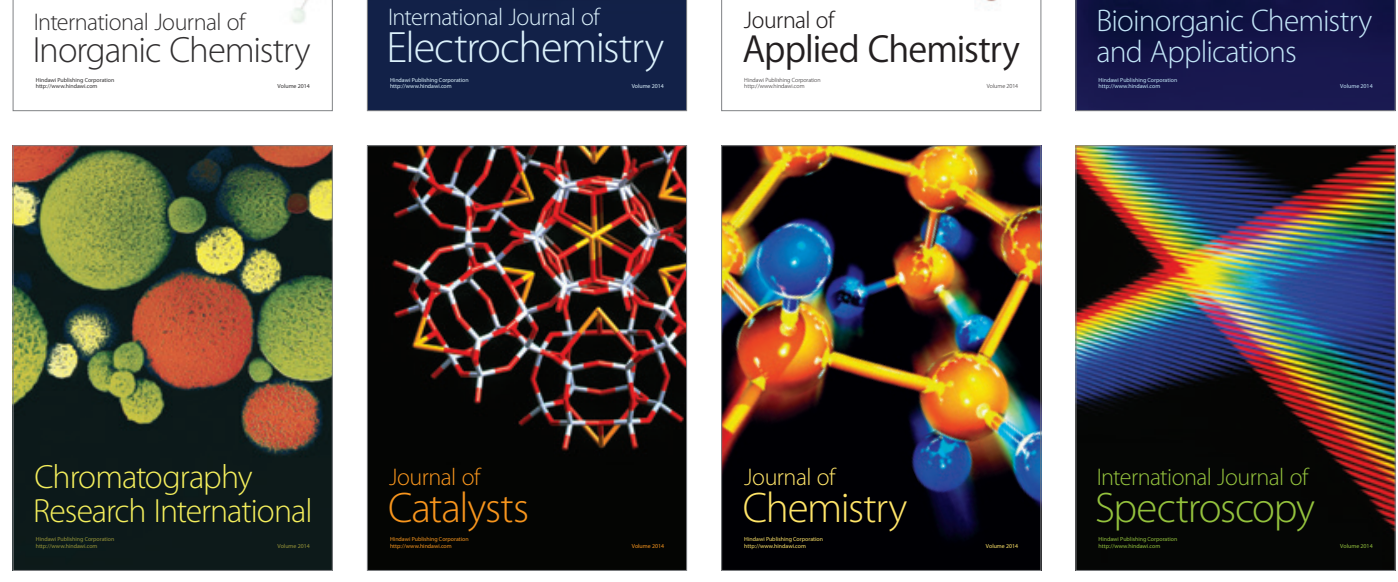